\title{
Questes
}

Revue pluridisciplinaire d'études médiévales

4 | 2003

L'arbre

\section{«Le végétal en fête ». Retour sur la symbolique végétale dans la liturgie}

\section{Andrea Martignoni}

\section{(2) OpenEdition}

1 Journals

Édition électronique

URL : http://journals.openedition.org/questes/1743

DOI : 10.4000/questes. 1743

ISSN : 2109-9472

\section{Éditeur}

Les Amis de Questes

\section{Édition imprimée}

Date de publication : 15 mai 2003

Pagination : 8-10

ISSN : 2102-7188

\section{Référence électronique}

Andrea Martignoni, « « Le végétal en fête ». Retour sur la symbolique végétale dans la liturgie »,

Questes [En ligne], 4 | 2003, mis en ligne le 01 janvier 2014, consulté le 15 septembre 2020. URL: http://journals.openedition.org/questes/1743

\section{(C) Association des amis de «Questes »}


Nul étonnement à ce que le lecteur soit invité à se promener lui-même en ce lieu, à lire à l'ombre des arbres comme le lui conseille Jean Robertet (Douze Dames de Rhétorique). Enserrant le livre de son attention toujours en mouvement, le récepteur se fait, non arbre, mais treille.

\author{
Par grant ardeur je m'essaye et traveille \\ d'en vous mouvoir vostre ententive oreille (...) \\ Par quoy s'en vous a veine qui someille \\ Je vous prie donc d'en susciter la treille \\ Et que le coeur s'expose et appareille \\ A enfonser ses mémoires labiles.
}

George Chastelain, Miroer des nobles hommes de France, VI, 206.

La «treille» de la lecture est une architecture interne de la mémoire, qui s'éveille à l'appel de la poésie. Elle enserre l'arbre-texte, le couvre de sa verdure et de ses fleurs pour que, par cette nouvelle richesse, il s'élance de nouveau vers la création.

\title{
«Le végétal en fête » \\ Retour sur la symbolique végétale dans la liturgie Andrea MARTIGNONI
}

Arbres, plantes et feuillages tiennent une place de première importance dans la liturgie et dans l'univers de la ritualité cérémonielle du Moyen Age. Leur puissance symbolique possède une fonctionnalité tout à fait performative dans le rituel. Arbre de vie et feuillage de printemps par exemple, sont au cœur de l'organisation et du déroulement des festivités pascales. Par le recours aux éléments végétaux dans l'actualisation de la scénographie cérémonielle précise et codifiée, le dimanche des Rameaux ou des Palmes réactualise et commémore l'entrée du Christ à Jérusalem. 
Lors du rite de la dédicace de l'église, c'est l'hysope qui est employée. Eric Palazzo a rappelé notamment que l'évêque, brandissant dans sa main l'hysope, procédait ainsi à l'aspersion des murs extérieurs de l'église. La fonction purificatrice de cette plante, dont témoigne la tradition textuelle biblique vétéro et néotestamentaire, participe pleinement à l'accomplissement symbolico-matériel du rituel.

Le végétal est en outre présent dans d'autres occasions liturgiques comme celles des cérémonies funéraires. Pensons au buis, à l'if, l'arbre psychopompe par excellence, et au frêne qui, aux dires de Danièle Alexandre-Bidon, était l'arbre d'immortalité dans les traditions scandinaves.

Les liturgistes des $\mathrm{XII}^{\mathrm{e}}$-XIII ${ }^{\mathrm{e}}$ siècles tels un Guillaume Durand de Mende avec son Rational ou Manuel des divins offices (achevé après 1285), évoquent à plusieurs reprises l'utilisation du végétal dans la vie liturgique surtout lors des «Pâques fleuries». Mais il suffit de consulter les registres de comptes qui détaillent les dépenses effectuées par les confréries et les communautés paroissiales à la fin du Moyen Age ainsi que les registres des délibérations communales, pour s'apercevoir que le végétal est un élément constitutif d'autres moments cérémoniels. Prenons brièvement appui sur les investigations menées dans les archives du Frioul (Nord-Est de Venise).

Le premier exemple concerne la fête du saint patron. Les dépenses effectuées par les confréries de san Giacomo et de san Cristoforo d'Udine, montrent qu'une somme d'argent était destinée annuellement à la commande d'une charrette remplie d'herbe et de buissons destinés à la décoration externe et interne de l'église confraternelle lors de la fête du saint patron, ici saint Jacques et saint Christophe.

Le second est celui de la fête du Corpus Christi. L'ensemble des délibérations communales du $\mathrm{XV}^{\mathrm{e}}$ siècle permettent de souligner la prédominance des commandes publiques de feuillages pour l'organisation annuelle des festivités du Corpus Domini. Au mois de mai 1428, pour ne citer 
qu'un exemple, la commune d'Udine condamne certains bourgs supérieurs de la ville pour n'avoir pas rassemblé la quantité d'herbe et de feuillages nécessaire à embellir et à recouvrir le trajet de la procession citadine organisée pour la fête. $\mathrm{Au}$ mois de mai 1458, le bourg de Grazzano se voit chargé par l'autorité communale de réunir une quantité suffisante d'herbe pour la répandre sur le parcours de ladite procession.

On a ici la confirmation de la coutume, bien ancrée dans la réalité liturgique et cérémonielle à laquelle pouvoirs communaux et ecclésiastiques participent, de décorer par de l'herbe et par des branches d'arbres fleuries l'intérieur de l'église mais aussi les espaces de la visibilité collective (rues et places) que le passage du cortège processionnel et festif sacralise, définissant à nouveau la géographie sacrée de l'espace urbain.

Par la présence du végétal, c'est toute une symbolique religieuse qui se renforce et qui s'exprime. Cette symbolique est profondément liée au cycle de la nature. Pâques, mais également le Corpus Christi du mois de mai, sont les temps forts de la vie liturgique de tout chrétien, comme la figure du saint patron pour la communauté confraternelle. Deux renaissances, une naturelle et l'autre spirituelle, qui s'emboîtent pour se compléter au sein de la codification rituelle. Comme le printemps annonce le renouvellement du cycle de la vie à nouveau fertile et féconde, le sacrifice du Christ ouvre les portes à une nouvelle existence spirituelle possible seulement après le rachat et la rédemption du péché originel. Symbole de régénération, le végétal dans ses différentes typologies est donc une présence constante dans la vie religieuse collective. 